Document downloaded from:

http://hdl.handle.net/10251/156319

This paper must be cited as:

Payri, R.; Bracho Leon, G.; Gimeno, J.; Moreno-Gasparotto, AE. (2019). Investigation of the urea-water solution atomization process in engine exhaust-like conditions. Experimental Thermal and Fluid Science. 108:75-84. https://doi.org/10.1016/j.expthermflusci.2019.05.019

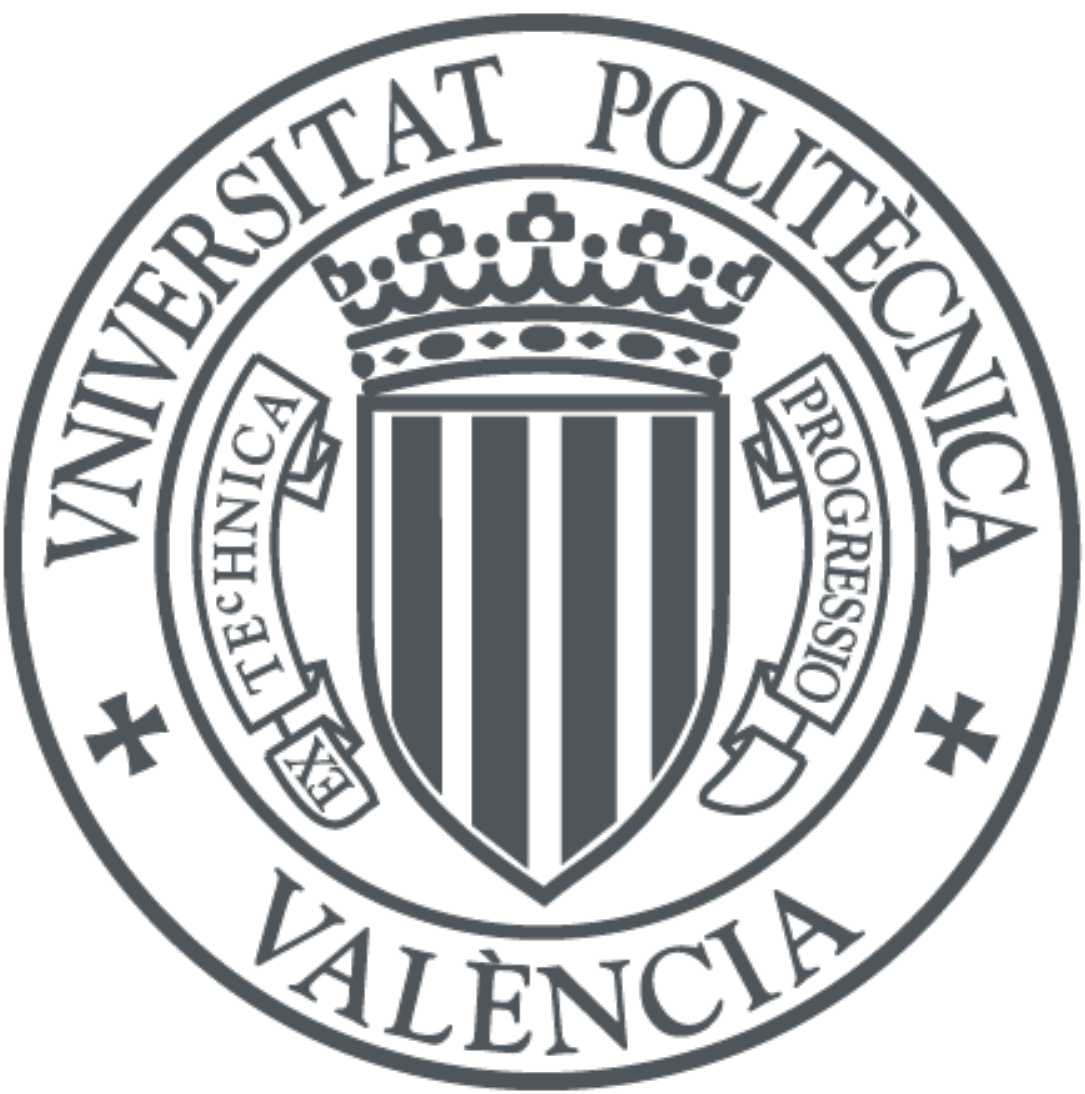

The final publication is available at

https://doi.org/10.1016/j.expthermflusci.2019.05.019

Copyright Elsevier

Additional Information 


\title{
Investigation of the Urea-Water Solution Atomization Process in Engine Exhaust-Like Conditions
}

\author{
Raul Payri, Gabriela Bracho*, Jaime Gimeno, Armando Moreno \\ CMT-Motores Térmicos, Universidad Politécnica de Valencia, Valencia, 46022, Spain
}

\begin{abstract}
The injection process of the urea-water solution (UWS) determines the initial conditions for the mixing and evaporation of the fluid in the selective catalytic reduction system. In this study, the liquid atomization process of a UWS dosing system is investigated using optical diagnosis through back-light imaging. The droplet diameter distribution and the droplet velocity (in the axial and tangential components) of the liquid spray are quantified under different air flow and injection conditions. A new test facility was designed to study UWS spray under conditions that resemble those of the engine exhaust pipe, which is capable of reaching an air flow of $400 \mathrm{~kg} / \mathrm{h}$ and air temperatures up to $400{ }^{\circ} \mathrm{C}$. The test matrix consisted of variations in the air flow temperature, air mass flow and UWS injection pressure. A high speed camera was used for capturing the images of the liquid spray, comparing the atomized liquid behaviour in three different regions of the plume: the first one near the nozzle exit, and the other two in the developed region of the spray (one aligned with the injector axis and the other at the spray periphery). Increasing the injection pressure affected the atomization process producing smaller particles with higher velocities in the axial and tangential components, promoting wider global spray angles, that combined with high air flow temperatures could improve the evaporation and mixing process in the SCR system. The main contribution is the development of an alternative technique for the quantification of the droplet size and velocity.
\end{abstract}

\footnotetext{
*Corresponding author. Email address: gbracho@mot.upv.es

Published as: Experimental Thermal and Fluid Science, 108 (2019) 75-84
} 
Keywords: Urea-Water Solution, Droplet Size, Droplet Velocity, Spray characteristics

\section{Introduction}

Environmental concerns and fuel consumption are still hot topics in the main forums related to internal combustion engine development. The emission challenges and the engine efficiency are commanding the directions for continuous improvement of internal combustion engines [1-3]. Thanks to the efforts of the industry and the scientific community, the technologies are rapidly evolving, especially in the improvement of several subsystems such as fuel injection components, combustion system and the after-treatment. For example, studies done by Triantafyllopoulos et al. [4] showed that for the enhancement in de$\mathrm{NO}_{\mathrm{x}}$ technologies, the preferential solution is the implementation of Selective Catalytic Reduction (SCR), which reduced the real drive emissions. The SCR works as a chemical reactor in conjunction with the injection of a Urea-Water Solution (UWS) upstream in the exhaust pipe [5]. The UWS mixes with the combustion gases, passing through a catalysts where the $\mathrm{NO}_{\mathrm{x}}$ byproducts of combustion are reduced with ammonia $\left(\mathrm{NH}_{3}\right)$ into water and nitrogen [6].

To ensure an effective de- $\mathrm{NO}_{\mathrm{x}}$ process, the UWS should vaporize before the flow reaches the inlet section of the SCR with an adequate distribution and correct quantity [5, 7]. Therefore, a good design should include rapid decomposition and uniform distribution of the urea.

The UWS injector is responsible for the correct dosing and homogeneous distribution of the droplets. The literature shows that substantial efforts are being done in the understanding and improvement of these systems, especially for a better comprehension of the UWS spray characteristics, from the global perspective (liquid spray penetration and spreading angle) and from local point of view (droplet velocity, shape and diameter distribution). In recent years, the interest in the determination of the global and local spray characteristics at different exhaust flow conditions has increased, basically because improper quantities of 


\begin{tabular}{|llll|}
\hline \multicolumn{2}{|l|}{ Nomenclature } & & \\
$a$ & droplet area & ASOE & As of Start Of Energizing \\
$\mathrm{CO}_{2}$ & Carbon Dioxide & $\mathrm{CFD}$ & Computational Fluid Dynam- \\
$D_{d}$ & Droplet Diameter & & ics \\
$D_{e q}$ & Equivalent Diameter & DBI & Diffused Back-Illumination \\
$\mathrm{NO}_{2}$ & Nitrogen Dioxides & $\mathrm{ET}$ & Energizing Time \\
$\mathrm{NO}_{x}$ & Nitrogen Oxides & LED & Light-Emitting Diode \\
$\Delta P$ & Pressure Difference & SCR & Selective Catalytic Reduction \\
$\rho_{g}$ & Density of the flow & UWS & Urea Water Solution \\
$\rho_{L}$ & Density of the fluid & & \\
& & & \\
\hline
\end{tabular}

urea-water spray may generate deposits that could block the exhaust lines and reduce the efficiency of the system. Many researchers have investigated the spray pattern of the UWS using both numerical and experimental approaches. On the experimental side, several works have been done using optical techniques in simplified facilities that allow to study the liquid jet in cross-flows. Some of those studies have been carried out injecting water instead of the UWS solution since the physical properties are similar. However, in other cases the use of urea is preferred, specially when deposits are the subject of interest. Studies by Oh and Lee [7] and Varna et al. [8] showed the importance of spray distribution, droplet diameter and wall impingement on the deposit formation and the $\mathrm{NO}_{\mathrm{x}}$ conversion efficiency. From the global perspective, spray imaging measurements were carried out by Van Vuuren et al. [9, 10] using an aqueous urea solution (AUS-32) in a hot air test bench, reaching both fluid and air temperatures of $130{ }^{\circ} \mathrm{C}$ and $490{ }^{\circ} \mathrm{C}$ respectively. They concluded that the temperature of the fluid had a strong influence on the global spray parameters, due to the atmospheric boiling point of the fluid. Meanwhile, gas temperature slightly affects the spray development. LeCompte et al. [11] evaluated the effect of exhaust pipe geometry, mixer location and gas temperature on the vaporization and 
homogenization of the mixture using optical diagnostics as well.

Droplet and velocity distributions have also been investigated. Concerning the velocity field, Spiteri and Dimopoulos-Eggenschwiker [12] described a test rig to characterize the spray flow field using a particle image velocimetry apparatus, providing mean velocity fields. Liao et al. [13] conducted measurements in the same test rig for determining the droplet size and velocity using phase doppler anemometry (PDA) before wall impingement. Although this laser based optical approach is widely used, the assumption of completely spherical particles might limit its application for some boundary conditions, such as low injection pressures and near the nozzle exit where blobs and ligaments also appear. Postrioti et al in [14] proposed a viable alternative based on back-light imaging for diameter determination and validated the results against PDA.

The objective of this paper is to determine the urea spray structure in terms of droplet size distribution and velocity in conditions analogous to those in the exhaust pipe of a combustion engine, for pressure, air flow and temperature. The estimations of the droplet size distribution are made using a back-light technique at three different positions of the spray plume: near the nozzle exit, and in the developed region of the spray. Furthermore, a novel procedure is used for the determination of the droplet velocity based on the back-light imaging at high speed acquisition rate and a particle tracking algorithm. This method is an alternative to the PIV, which only provides averaged flow velocities, or to PDA and other related method that are based on spherical droplets. The quantification of the droplet size distribution and velocity is necessary in order to provide robust experimental data for computational fluid dynamic models, as boundary conditions or for validation purposes.

The manuscript is divided into four sections. After the introduction, the experimental facility is described, along with the details of the optical configuration and the image processing implemented. The results are presented and discussed next for the measured parameters. Finally, the conclusions obtained through the execution of this work are presented. 


\section{Materials and Methods}

The urea-water solution spray development was analyzed experimentally using a new installation designed at the facilities of Centro de Motores Térmicos (CMT). It is capable of reaching high gas flow and temperature and is explained in detail in the following subsections.

\subsection{High Flow and Temperature Installation for Urea-Water Solution (UWS)}

\section{Spray Visualization}

The test rig reproduces realistic conditions of flow inside the exhaust pipe and is connected to a chamber with four optical accesses (showed in Figure 1). The facility is composed of a centrifugal blower, hot-wire flow meters, a $15-\mathrm{kW}$ electric heater and a visualization chamber that was used to carry out the optical measurements. The installation has a wide operation range, allowing boundary conditions of flow and temperature up to $400 \mathrm{~kg} / \mathrm{h}$ and $400{ }^{\circ} \mathrm{C}$ respectively. The test rig inhales air from its surroundings through the centrifugal compressor, and then sent to the electric heater controlled by a PDI set at the desired measurement temperature. The flow enters the visualization vessel where the UWS spray is injected into the hot air stream.

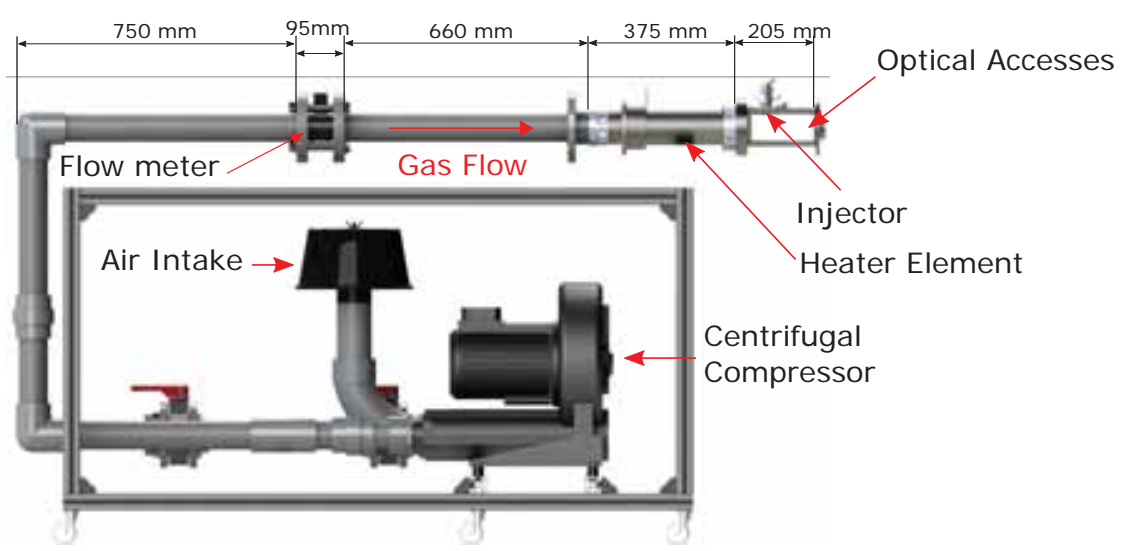

Figure 1: High Flow and Temperature Installation. 
The visualization vessel (in Figure 2) has four optical accesses allowing direct visualization of the Urea-Water Solution (UWS) spray. The design is modular, and it can be easily rearranged to simulate various configurations of the injector position and the exhaust pipe. For this work the UWS injector is mounted perpendicular to the air flow, in such manner that the whole spray development can be registered.

The dosing unit used was a commercial injector developed for diesel SCR application. Its nozzle has three holes with a diameter of $135 \mu \mathrm{m}$ each. Nevertheless, the images indicated that the cone spray produced by each hole merged to a single plume. The tip is refrigerated with a cooling fluid at a temperature of $60{ }^{\circ} \mathrm{C}$. The details of the injector are described in table 1 .

Table 1: Injector properties.

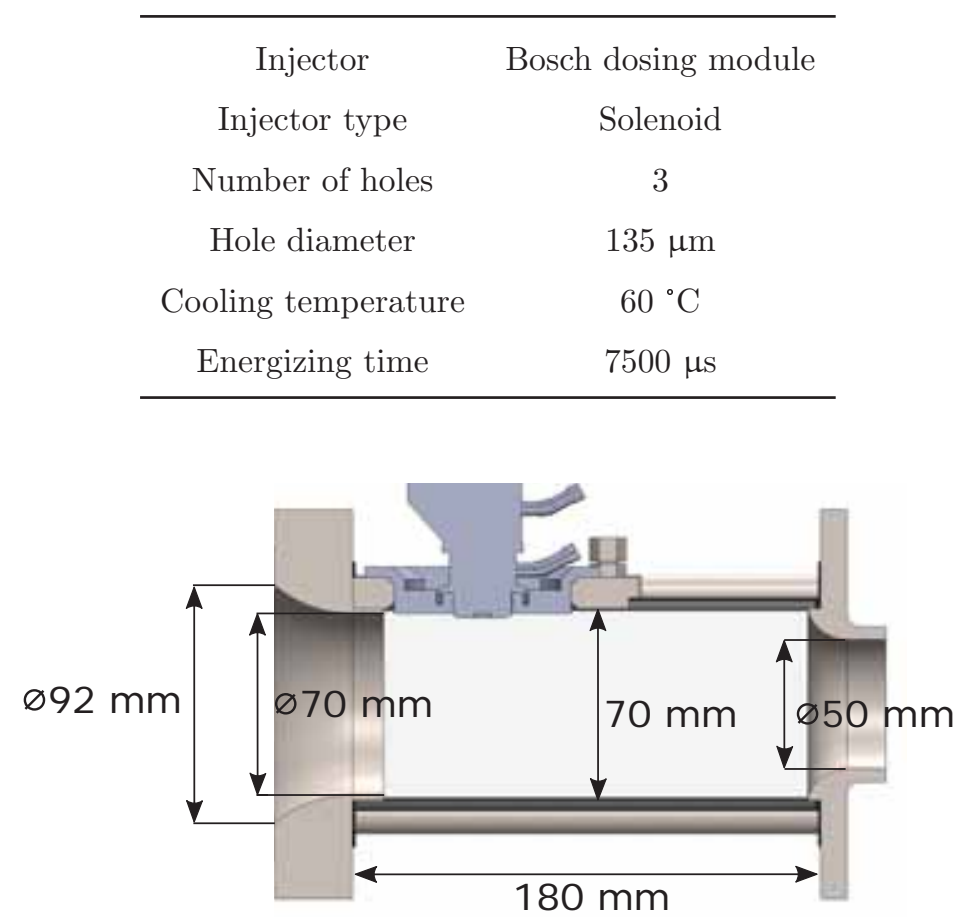

Figure 2: Configuration of the optically-accessible section. The air flow moves from left to right 


\subsection{Optical Technique and Setup}

In order to study the liquid spray characteristics of the UWS injection process, a diffused back-illumination (DBI) technique was applied to visualize the spray. Light emitted from a source, a light-emitting diode (LED) in this case, is passed through a diffuser and is reproduced in the spray plane by a Fresnel lens. The rays that were not blocked by the spray are captured by a camera, thus rendering the liquid phase as a shadow or dark pixels in the images. The use of a high-speed pulsing LED as illumination makes this optical setup the best option for liquid phase visualization of the spray. Coupled with a high-speed camera, this setup allows to capture sharper images than with continuous light sources, as the pulse has a controlled duration of $500 \mathrm{~ns}$, thus reducing the actual timing and spatial uncertainties of the captured image.

The DBI was carried out with a Photron SA5, equipped with a Nikon Sigma 24-70mm lens, for an acquisition rate of $31 \mathrm{Kfps}$ and a spatial resolution of 7.3 pix $/ \mathrm{mm}$. Figure 3 shows the optical arrangement employed. For the near-field visualization campaign, the same equipment was used, coupling the camera to an Infinity K2 DistaMax lens, allowing the enhancement of the resolution to $40.2 \mathrm{pix} / \mathrm{mm}$, and enabling the visualization and tracking of the UWS spray droplets by acquiring images at $150 \mathrm{Kfps}$, with a depth of field of $1 \mathrm{~mm}$. Some details of the optical setup are presented in Table 2.

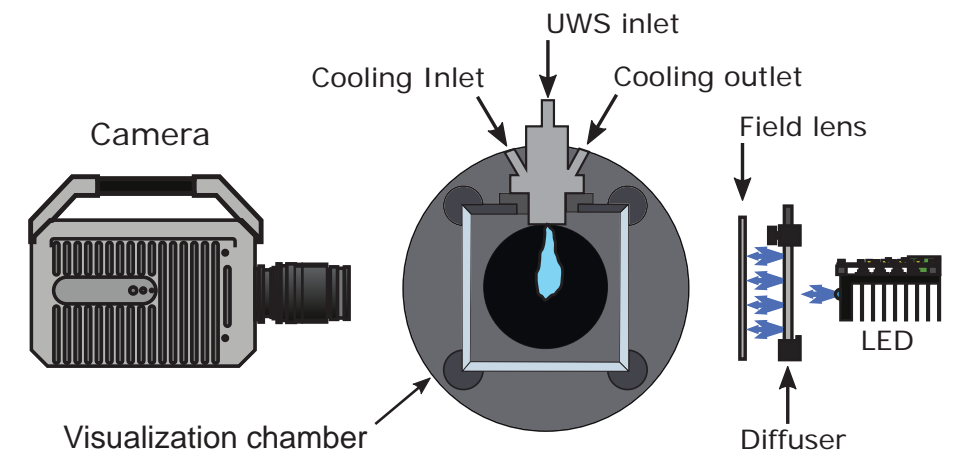

Figure 3: Scheme of the optical setup used for Diffused Back-Illumination (DBI): global spray; UWS:Urea-Water Solution, LED: Light Emitting Diode 
Table 2: Details of the optical setup for the employed techniques.

\begin{tabular}{|c|c|c|c|c|c|c|c|}
\hline & Camera & Lens & $\begin{array}{c}\text { LED } \\
\text { Pulse Duration }\end{array}$ & $\begin{array}{c}\text { Frame } \\
\text { Rate }\end{array}$ & Resolution & Pixel-mm & Repetitions \\
\hline DBI: Global Spray & \multirow{2}{*}{ Photron SA5 } & Nikon Sigma 24-70mm & $500 \mathrm{~ns}$ & 31.000 & $384 \times 976$ & 7.3 & \multirow{2}{*}{10} \\
\hline DBI: Near-Field Spray & & K2 DistaMax & $200 \mathrm{~ns}$ & 150.000 & $256 \times 216$ & 40.2 & \\
\hline
\end{tabular}

\subsection{Image Processing}

To analyse the data obtained with the DBI technique, a systematic algorithm is applied in order to extract the properties of the spray. The methods employed in this work are described below.

\subsubsection{Contour Determination}

The first step was to define the general shape of the spray that would assist in the definition of the locations for the near-field visualization windows, ensuring that they are within the spray boundaries. Besides, this methodology is often used for determining other global spray parameters like the spray penetration and the angle, as was reported by Payri et al [15].

The camera was configured to record images every $32 \mu \mathrm{s}$. This short time gap was possible thanks to the adquisition rate of the equipment. A short light pulse emitted by the LED was used to freeze the image. This allowed an accurate detection of the spray evolution in time. Figure 4 shows an example of the images obtained through the setup explained in the previous subsection. In general, the methodology described by Payri et al [16-19] was followed in order to obtain the spray information:

- Background correction: To remove reflections and back-drop objects that could generate bad estimations of the spray, the background is taken as the image acquired before the start of injection and is subtracted arithmetically from spray images.

- Spray boundaries detection: The approach proposed by Siebers[20] was employed to analyse diesel sprays, where the spray boundary is calculated by binarizing the image. The images in general showed the evolution 
of a dark shadow that represented the liquid phase of the spray. However, some regions of the frames also depicted lighter gray shades that might correspond to droplets that are evaporating or out of the focal plane. The binarization threshold was kept high enough to mitigate the noise related to the background camera sensor noise or beam steering but low enough to ensure a robust detection of the liquid. After an iterative procedure based on previous experiments for determining the threshold, the best trade-off was found for a value corresponding to $5 \%$ of the dynamic range of each frame.

- Contour analysis: Once the contour of the spray was obtained, it was possible to calculate the geometrical features showed in Figure 5 [15]. This allowed to locate properly the positions for the microscopic study of the spray.

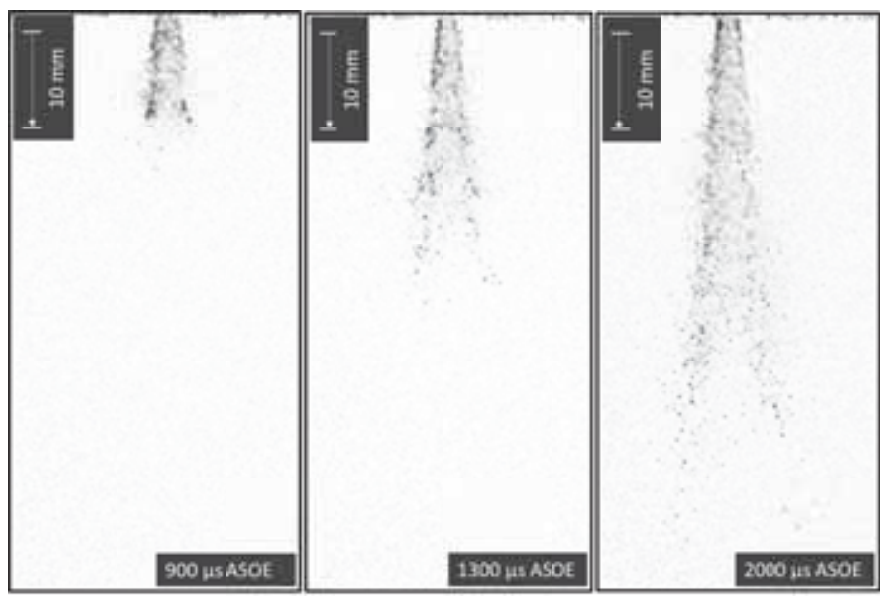

Figure 4: Spray image series seen by the DBI image processing method. $\left(\mathrm{T}_{\text {air }}=350{ }^{\circ} \mathrm{C}, \mathrm{P}_{\text {inj }}\right.$ $=8 \mathrm{bar}$, gas flow $=40 \mathrm{~kg} / \mathrm{h})$. Referenced to the time ASOE. 


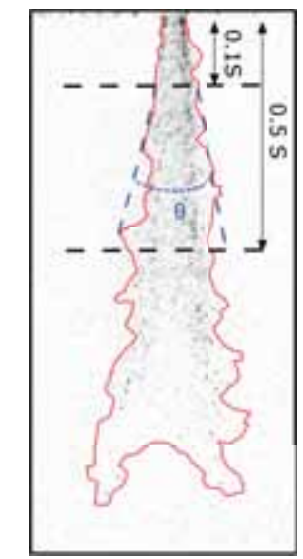

Figure 5: Spray countour determination methodology example.

\subsubsection{Droplet Size Determination}

For the near-field visualization, the general configuration presented in Figure 3 was used, but replacing the the Nikon Sigma lens with the K2 DistaMax microscopic lens, which allows a more detailed visualization of the spray. With the magnification provided by this lens, droplets of the UWS spray can be seen and measured, allowing the determination of their diameter, trajectory, and velocity. Three measuring windows were selected for the droplet size imaging: Position 1 (P1) at $4 \mathrm{~mm}$ below the nozzle exit, Position 2 (P2) on the axis of the injector at $30 \mathrm{~mm}$ from the nozzle exit, and Position 3 (P3) as far from the nozzle as P2, but $7 \mathrm{~mm}$ off axis in the direction of the flow (see Figure 6). All measurement positions were recorded in an optical window of $4.1 \mathrm{~mm}$ in height and $3.8 \mathrm{~mm}$ in width (not to scale in the drawing). The characteristics of the optical configuration are detailed in Table 2. 


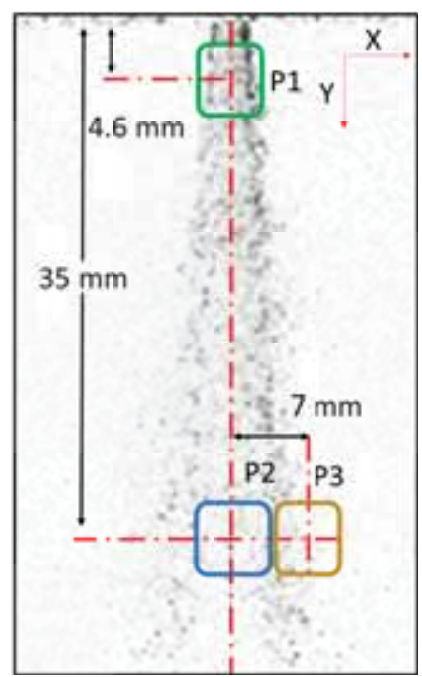

Figure 6: Definition location of the windows used for the near-field visualization (not to scale); P1: Position 1, P2: Position 2, P3: Position 3.

The main difficulty of this setup is the small depth of field of approximately 1 $\mathrm{mm}$. Thus, some of the droplets appear out of focus. To overcome this problem the images were processed in the following way:

- Out of focus droplet filtering: The unfocused structures on the frame were filtered using a dynamic threshold. These droplets have low contrast and appear more blurred the further away they are from the focal plane.

- Image binarization: With the idea of making the determination of properties easier, after the filtering has been finished, a binarization of the image takes place.

- Properties determination: For each detected droplet, several properties can be extracted using an image processing tool developed in MATLAB. It is focused on obtaining the area of the droplets and their location coordinates for each time step.

- Droplet filtering by residence time: During the measurement, many droplets appear in focus just for a couple of frames. In order to keep only those 
droplets that could be tracked, as will be explained in Section 2.3.3, the droplets found with this method are cross referenced with the one used to calculate the velocity of the droplets, and only the matching droplets were kept.

A comprehensive approach of droplet visualization and image processing can be found in the studies of Manin et al. [21] and Blaisot and Yon [22].

\subsubsection{Droplet Velocity}

Another advantage of the microscopic visualization setup is the ability to track down droplets for each frame to determine their velocity. This is achieved by taking into account only those that comply with certain parameters, which are:

- Droplet detection: After the background was removed and the threshold was applied to each image, the properties of size and location were obtained (as showed in Figure 7), and the resulting filtered image was then used to track the droplets. This step goes along with the determination of the droplet size.

- Frame to frame position: A search radius was defined to help the algorithm locate particles that have similar properties in consecutive frames (Figure 8). Thanks to the recording speed of 150,000 frames per second, the size of the search radius became smaller, avoiding most of the interference with other droplet search regions.

- Residence time: As mentioned in Section 2.3.2, the volume in which the droplets were detected is small, and some droplets might pass through this space, staying in focus for a short time. In order to filter these droplets, a residence time was set, which allowed the algorithm to ignore those that did not appear in the images for a given number of frames. 


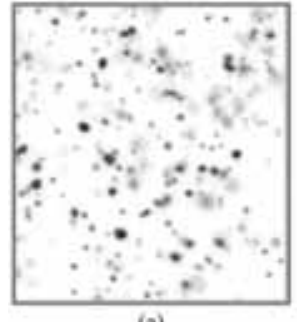

(a)

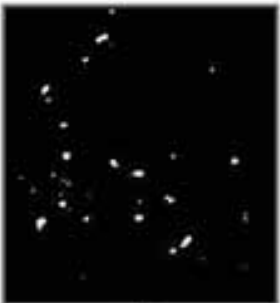

(b)

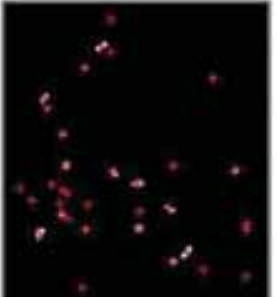

(c)

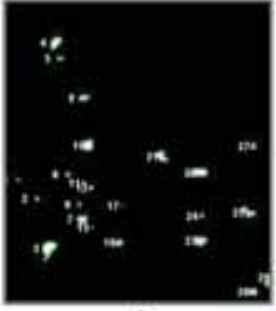

(d)

Figure 7: Steps to detect the droplets for each frame:(a) Image with background subtracted, (b) binarized image, (c) droplet detection, and (d) tagged droplets.
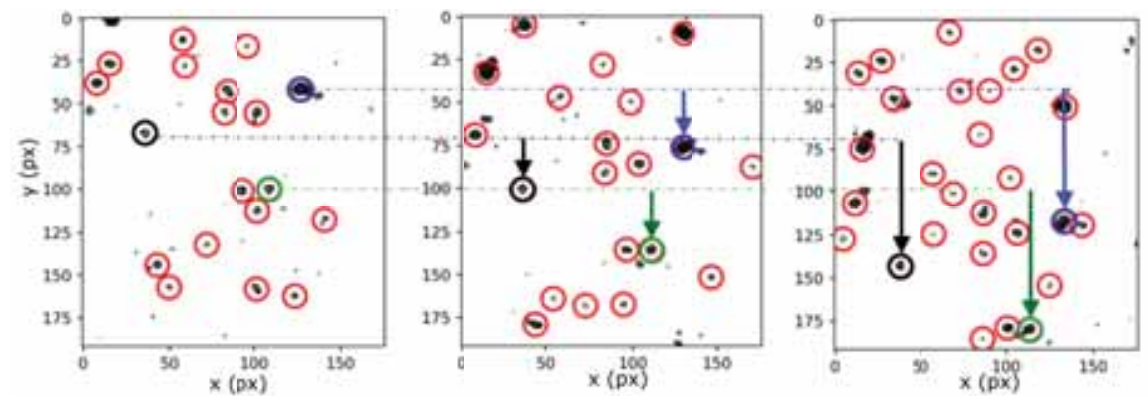

Figure 8: Location on the Y axis of droplets at Position 2 (P2) at (a) $1780 \mu \mathrm{s},(\mathbf{b}) 1806 \mu \mathrm{s}$, and (c) $1838 \mu \mathrm{s}$; Referenced to the time ASOE.

The information of the position in each time step is used to track a trajectory, as shown in Figure 9.

The velocity in each direction of every droplet is calculated by subtracting frame-to-frame its position and then dividing it by the time step, as shown in the equation:

$$
U_{i}=\frac{X_{t_{i}}-X_{t_{i-1}}}{\Delta t}
$$

Where $U_{i}$ is the Velocity of the droplet between the frames, $X_{t_{i}}$ and $X_{t_{i-1}}$ its coordinates in each image and $\Delta t=6.6 \mu$ s is the time between each frame. The mean velocity of the droplet was estimated as the average of all the values obtained. 


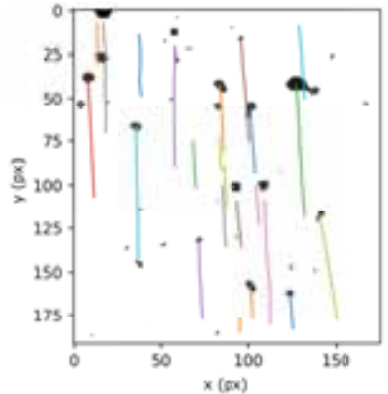

(a)
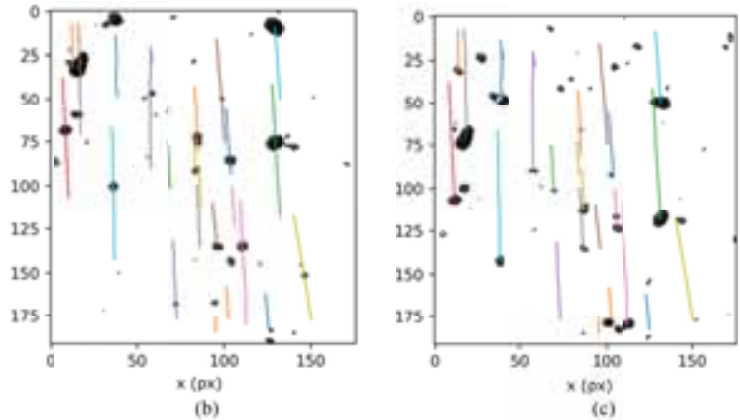

Figure 9: Trajectory of droplets at P2 at (a) $1780 \mu \mathrm{s},(\mathbf{b}) 1806 \mu \mathrm{s}$, and (c) $1838 \mu \mathrm{s}$ ASOE.

\subsection{Test Conditions}

The experiments were performed using the three-hole injector detailed in Table 1. The fluid used was AdBlue, which properties are described in Table 3. The experiments were performed in accordance with the conditions summarized in the test matrix shown in Table 4, with 10 repetitions per test point.

Table 3: Fluid properties for AdBlue.

\begin{tabular}{rc}
\hline Density at T $20{ }^{\circ} \mathrm{C}$ & $1087-1093 \mathrm{~g} / \mathrm{cm}^{3}$ \\
Viscosity at T $25^{\circ} \mathrm{C}$ & $1.4 \mathrm{mPa} \cdot \mathrm{s}$ \\
Surface tension at T $20{ }^{\circ} \mathrm{C}$ & $65 \mathrm{mN} / \mathrm{m}$ \\
\hline
\end{tabular}

Table 4: Test conditions.

\begin{tabular}{ccc}
\hline Parameter & Value & Unit \\
\hline Injection Pressure & $4-6-8$ & $\mathrm{bar}$ \\
Gas Mass Flow & 40 & $\mathrm{~kg} / \mathrm{h}$ \\
Gas Temperature & $180-350$ & ${ }^{\circ} \mathrm{C}$ \\
\hline
\end{tabular}




\section{Results}

\subsection{Effect of Injection Pressure on the Droplet Size Distribution}

Figure 10 shows three images at position 1 (top row) and three frames at position 2 (bottom row), for the three pressure levels tested at $180{ }^{\circ} \mathrm{C}$ and the time step corresponding to $3 \mathrm{~ms}$ after start of energizing (ASOE). At this time step the injection event is stabilized, with no influence of the opening or closing of the needle. From these frames it can be seen that in position P2 most of the droplets were spherical. However, at location P1 there were some other regions of liquid with non-spherical structures, like blobs or ligaments, that were still breaking up. Similar observation was previously reported by Postrioti et al[14], done at positions far from the nozzle exit, where they also registered the appearance of some non-spherical blobs.

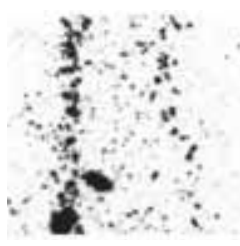

A

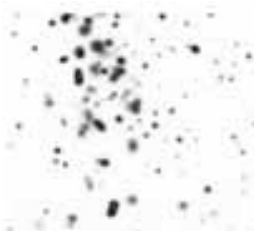

D

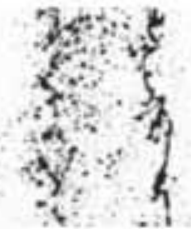

B

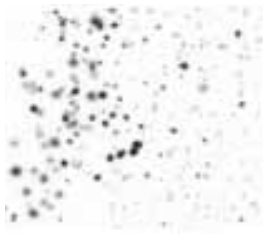

E

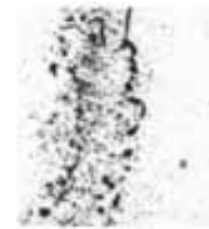

C

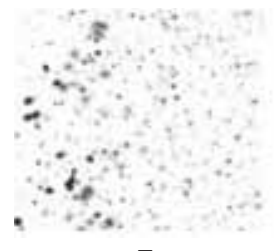

$\mathrm{F}$

Figure 10: Images of the urea-water-solution droplets at P1 (top row) and P2 (bottom row) for the three injection pressures. From left to right: (a and d) 4 bar, (b and e) 6 bar, and (c and f) 8 bar at $180{ }^{\circ} \mathrm{C}$.

After evaluating the morphology of the droplets that were successfully tracked it was decided to standardize all the non-spherical and ligament shapes, calculating an equivalent diameter of all the contours detected using the relationship:

$$
D_{e q}=\sqrt{\frac{4 a}{\pi}}
$$


Where $D_{e q}$ is the equivalent diameter and $a$ is the estimated droplet area. This process was applied to each time step of the injection event during the stable phase (not considering the opening and closing transient) and for all 10 repetitions, analysing approximately 6000 frames per test condition.

Since the injected mass is proportional to the square root of the pressure difference between the line and the vessel, the number of droplets for each injection pressure should be proportional to this parameter. In fact, the number of droplets found were in average $10 \%$ and $25 \%$ higher with the increase of the injection pressure from 4 to 6 and 8 bar, respectively. To be able to draw comparisons between measurement points, a normalized probability distribution[23] was calculated as is depicted in Figure 11, for the three positions and injection pressures. Even though a wide range of diameter size distribution was captured, the minimum diameter detected with this setup was limited to $21.7 \mu \mathrm{m}$, due to the optical zoom restriction and pix/mm relation. However, as Varna et al [8] and Postrioti [14] reported for similar conditions, the number of droplets with a diameter below $25 \mu \mathrm{m}$ could be considered negligible.

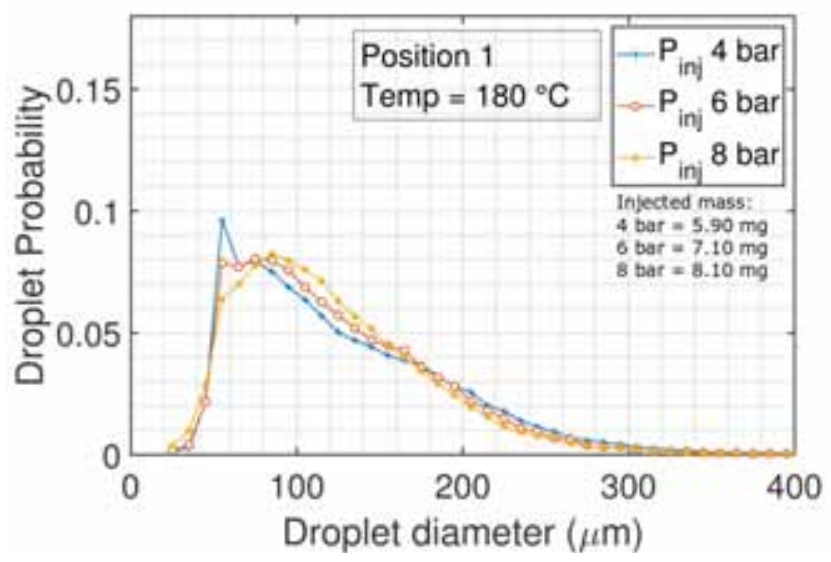

Figure 11: Distribution of the droplet diameter at P1 (near the nozzle exit) for the three injection pressures.

In the position near the nozzle exit (position 1), the injection pressure influenced the droplet quantity and size distribution. Figure 11 shows the droplet 
distribution curves for each injection pressure in this position. For the smaller droplets $(21 \mu \mathrm{m}$ to $45 \mu \mathrm{m})$ the three curves behave similarly. Injection pressure of 8 bar has a higher droplet probability in the range between $80 \mu \mathrm{m}$ and $180 \mu \mathrm{m}$ and for droplets with diameters above $200 \mu \mathrm{m}$ the tendency reverts, depicting a higher droplet probability for the injection pressure of 4 bar. The overall values obtained in this work were in the same order of magnitude as those found by other authors $[8,14,24,25]$.

Figure 12 shows the distribution of the droplet size at the region of interest in position 2, far from the nozzle exit. Injection pressures of 6 and 8 bar have a higher proportion of droplets with diameter below $50 \mu \mathrm{m}$ than the one of 4 bar. The mode of the three distributions is at $50 \mu \mathrm{m}$, and between this diameter and $110 \mu \mathrm{m}$ the 8 bar curve has a higher probability than the rest. After the 110 $\mu \mathrm{m}$ diameter the 4 bar curve has higher values than the 6 and 8 bar curves as was observed in Position 1.

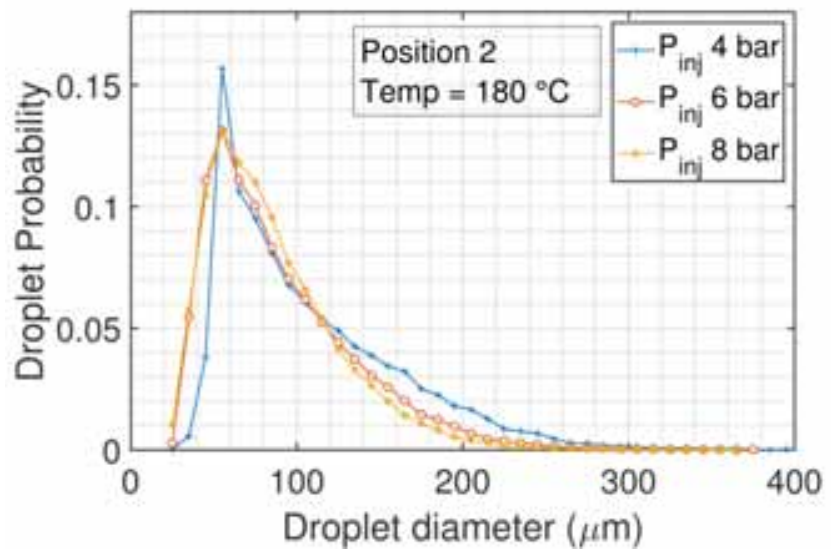

Figure 12: Distribution of the droplet diameter at P2, for the three injection pressures.

In position 3, showed in Figure 13, the trends of the distributions are similar to position 2, with a mode of $45 \mu \mathrm{m}$ for the injection pressures of 4 and 6 bar and $55 \mu \mathrm{m}$ for the 8 bar curve. Between 55 and $110 \mu \mathrm{m}$ the 8 bar curve has a higher proportion of droplets and for diameters bigger than $110 \mu \mathrm{m}$ the 4 bar 
curve becomes higher than the rest. The difference in the distribution curves is small compared to what was observed in Figure 12, meaning that as the region of interest is moved away from the spray axis the effect of the injection pressure is less noticeable in terms of droplet distribution.

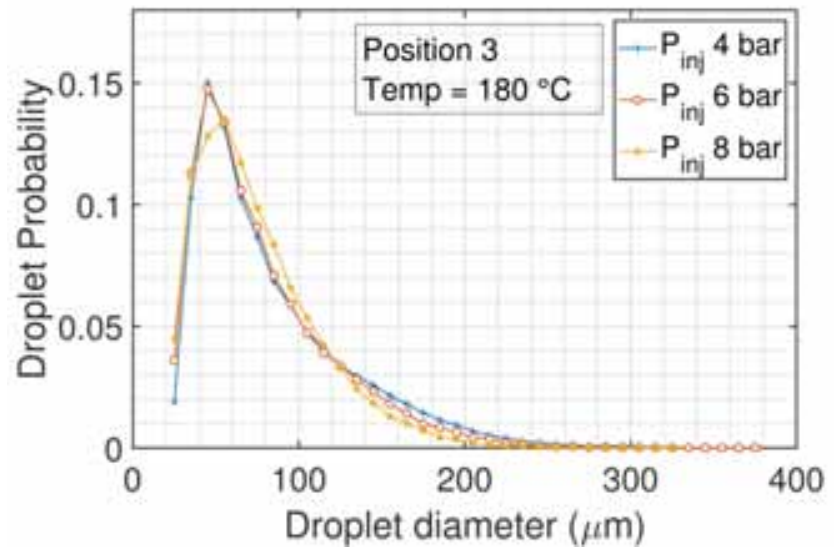

Figure 13: Distribution of the droplet diameter at P3, for the three injection pressures.

Moreover, in regions further away from the nozzle, the proportion of big droplets with a diameter above $100 \mu \mathrm{m}$ decreased, evidencing that some atomization process or evaporation took place at the developed zone of the spray. The confidence of the data obtained in this work are based on references found in the literature that compared the DBI technique versus the PDA, finding good agreement in the results $[14,22]$. Those reports were done at spray positions far from the nozzle exit, where most of the particles are spherical. Moreover, in the near nozzle region the spray is more dense and the droplets are not spherical and could have any other shape, as ligaments or blobs. Here the validation is more restricted, and from the authors knowledge there is very limited information available.

\subsection{Effect of Injection Pressure on the Droplet Velocity}

A similar approach as the one shown in the previous section was used to compare the velocity of the droplets in the injector axis ( $\mathrm{Y}$ component) and in 
the flow direction axis (X component).

\subsubsection{Velocity in the $Y$ Axis}

The droplet velocity distribution in the region close to the nozzle exit is plotted in Figure 14. Higher injection pressure provides more energy present in the fluid, then the droplets have a faster velocity in the vertical axis. Besides, the pressure increase results in an asymmetric distribution in the droplet velocity. At 8bar the velocity distribution peak is shifted towards the right. The behaviour is different at 4 bar, where the values have a narrow normal distribution with a mean of $23 \mathrm{~m} / \mathrm{s}$, comparable to the theoretical Bernoulli velocity at those conditions in the nozzle exit (approx. $24.4 \mathrm{~m} / \mathrm{s}$ ).

Figure 15 shows the velocity distribution curves for position 2. The behaviour with the injection pressure is similar to what was observed in position 1, finding higher velocity of the droplets as this parameter is increased. Unlike the previous position, the shape of the curves are similar and the mean velocity is lower for the three injection pressures. The homogenization of the curves can be attributed to atomization processes happening between positions and to the drag generated by the gas.

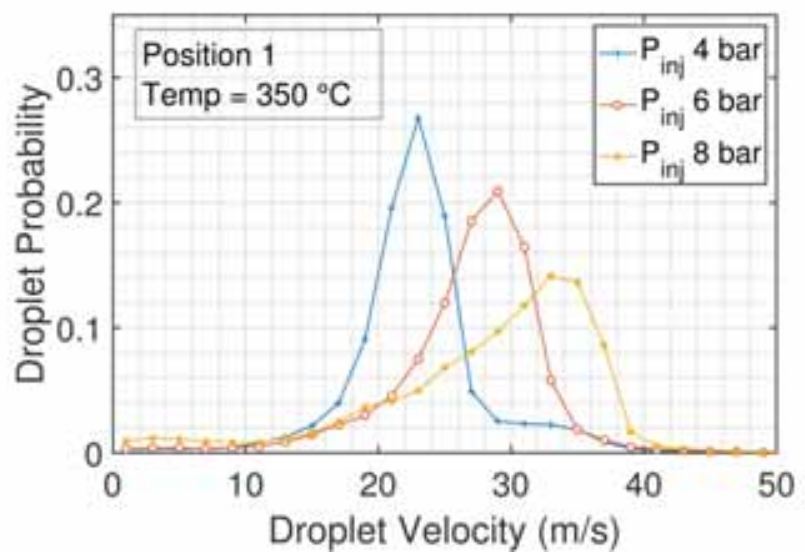

Figure 14: Distribution of the droplet velocity in the $\mathrm{Y}$ axis at $\mathrm{P} 1$, for the three injection pressures. 


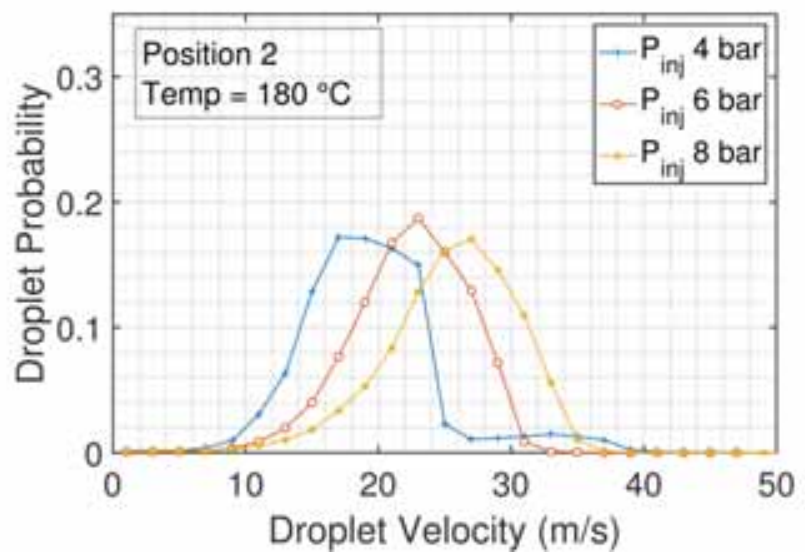

Figure 15: Distribution of the droplet velocity in the $\mathrm{Y}$ axis at $\mathrm{P} 2$, for the three injection pressures.

Finally, in Figure 16, the droplet distribution for P3 shows how for this off-axis position, the curves for the three cases had a uniform shape, as injection pressure was increased, the mean value of the distribution shifted toward faster velocities. In comparison with position 2 the distributions have a wider range, especially for the 4 bar curve, meaning that there are more droplets with different velocities in this position.

If velocity values are compared between the three positions for the same injection pressure, a general deceleration is observed as the droplets move far from the nozzle due to the momentum exchange with its surrounding and to the interaction of the UWS with the flow (that tends to deflect the spray in the direction of the gasses) [15]. 


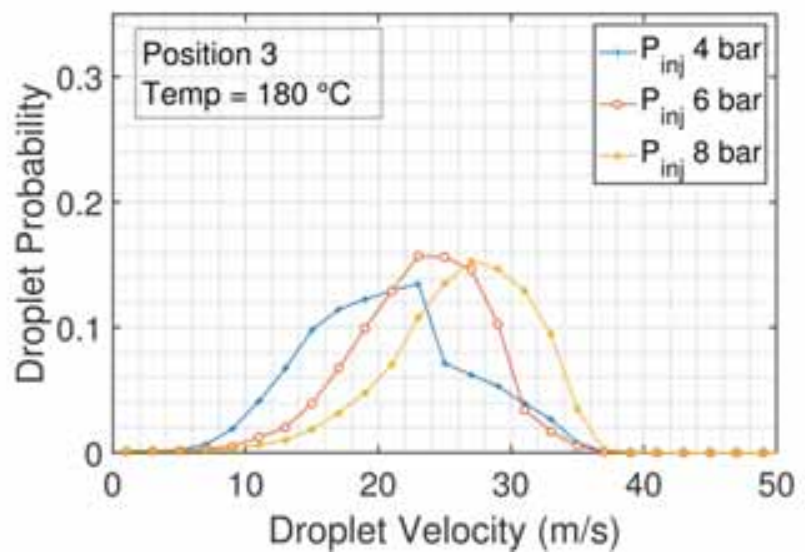

Figure 16: Distribution of the droplet velocity in the $\mathrm{Y}$ axis at P3, for the three injection pressures.

The results obtained for this component of the velocity are in concordance with the ones found in other studies [14, 26, 27], showing that the processing methodology used in this work is a viable alternative to measure droplet velocity.

\subsubsection{Velocity in the $X$ Axis}

The following figures present the results for the X component of the velocity. Figure 17 shows that the range of the velocity distribution has negative and positive values, meaning that droplets travelled in both directions (left and right) suggesting a spreading of the spray from the nozzle exit. Furthermore, the distribution became wider as the injection pressure rose, which may be attributed to slightly higher turbulence inside of the nozzle that moves the flow in the tangential direction [28]. This is in agreement with global spray angle results presented in [15], where higher injection pressure produced wider plumes. 


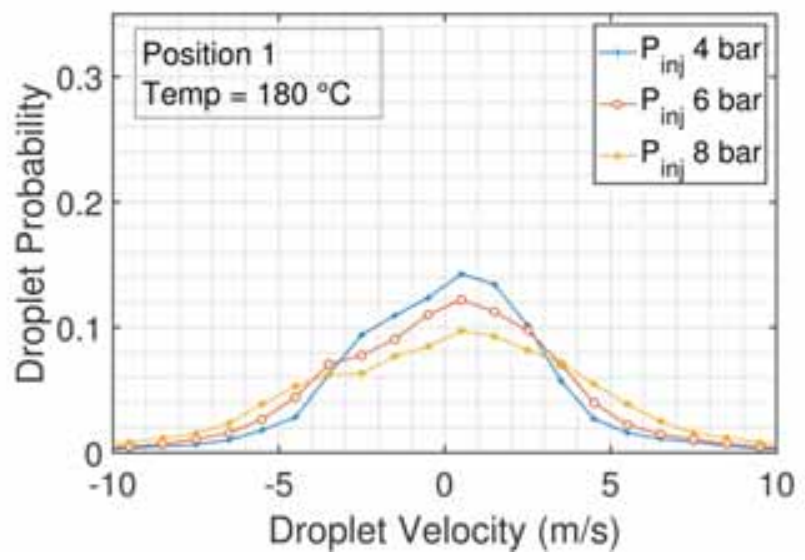

Figure 17: Distribution of the droplet velocity in the $\mathrm{X}$ axis at $\mathrm{P} 1$, for the three injection pressures.

At position 2, showed in Figure 18, the distribution of the droplets velocity had the same range for all injection pressures. It is noticeable that at this position the distribution is narrow and symmetric because in this region most of the droplets observed are those that travelled straight down from the nozzle and are not being deflected by the air flow.

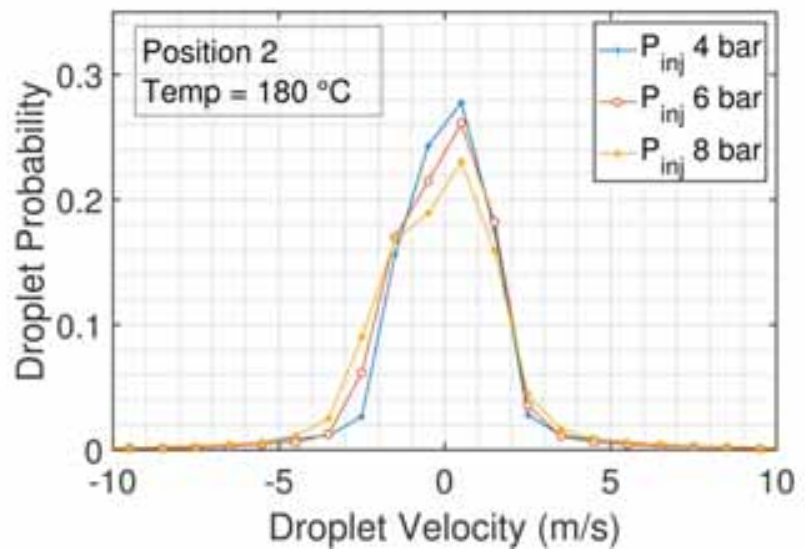

Figure 18: Distribution of the droplet velocity in the $\mathrm{X}$ axis at P2, for the three injection pressures. 
Figure 19 presents the results of the X component of the velocity at P3 for the three injection pressures, showing a similar behaviour in terms of distribution range and shape. Moreover, the droplets captured in this region have the highest velocity of the 3 positions, in the gas flow direction.

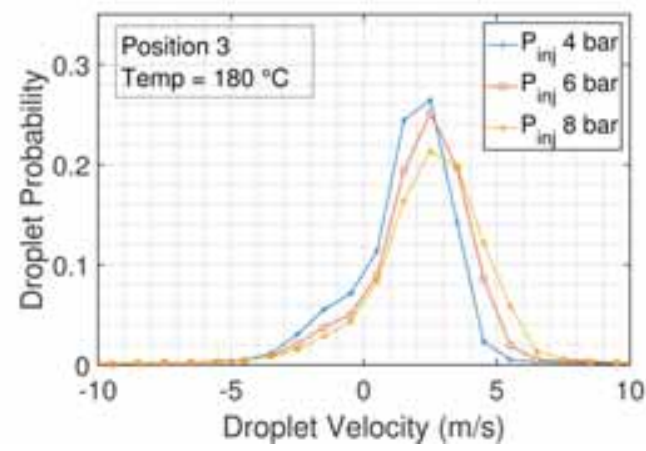

Figure 19: Distribution of the droplet velocity in the $\mathrm{X}$ axis at $\mathrm{P} 3$, for the three injection pressures.

\subsection{Effect of the Flow Temperature on Droplet Velocity}

In Figures 20 and 21, the influence of the temperature of the flow on the velocity of the droplets is presented. In the closest position to the nozzle, there was not an important effect on the droplet velocity distribution shape for both components due to the short distance from the exit orifices and the short exposure of the spray to the flow.

Nevertheless, the curves representing the flow temperature of $350{ }^{\circ} \mathrm{C}$ are slightly displaced towards a higher velocity. When the temperature of the gas is increased its density becomes smaller and since the gas flow is set to $40 \mathrm{~kg} / \mathrm{h}$ and the section area is constant for all test points, its velocity increases to mass flow conservation $(\dot{m}=\rho \cdot \mathbf{v} \cdot \mathbf{A})$. This could explain the increase of velocity observed in Figure 21 at positions 2 (middle) and 3 (right). Additionally, the effect of increasing temperature of the gas flow affects its viscosity facilitating the penetration of the fluid in the chamber, in agreement with the results of the macroscopic spray characterization of the same injector studied by Payri et al 
$[15] .$.
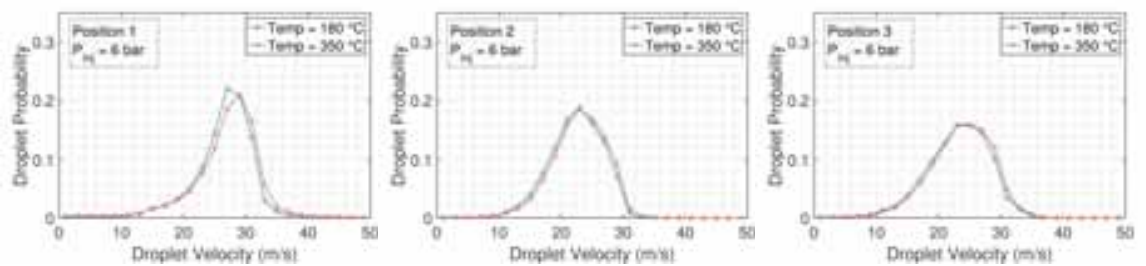

Figure 20: Distribution of the droplet velocity in the Y axis at P1 (left), P2 (center), and P3 (right), for the two flow temperatures.
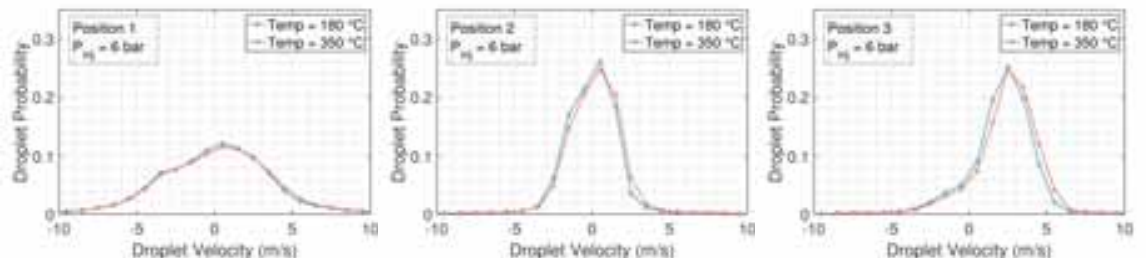

Figure 21: Distribution of the droplet velocity in the $\mathrm{X}$ axis at P1 (left), P2 (center), and P3 (right), for the two flow temperatures.

\subsubsection{Droplet Diameter - Velocity Summary}

As a summary of the results presented above, Figure 22 shows the relationship that exist between the velocity of the droplets and their size, corresponding to the injection pressure of 4,6 and 8 bar and $180{ }^{\circ} \mathrm{C}$ at position $\mathrm{P} 1$. The upper part of Figure 22 shows a three dimensional plot of the joint normalized droplet size and velocity distributions. In the case of the velocity of the droplets, the normalization is done considering the ideal exit velocity from the nozzle as $U_{o}=\sqrt{\frac{2 \Delta P}{\rho_{L}}}$. As for the droplet size, the normalization takes into account the mass median diameter(MDD), which is obtained by calculating the volume in each interval of the distributions as $\Delta Q_{i}=\Delta N_{i}\left(\frac{\pi}{6}\right)\left[\frac{1}{2}\left(D_{i 1}+D_{i 2}\right]^{3}\right.$, where $\Delta N_{i}$ is the number of droplets in each interval and $D_{i 1}$ and $D_{i 2}$ the boundary diameters of said interval, then the MMD is the diameter where the cumulative sum of the volume in the intervals equals $50 \%$ of the total liquid volume [28]. 

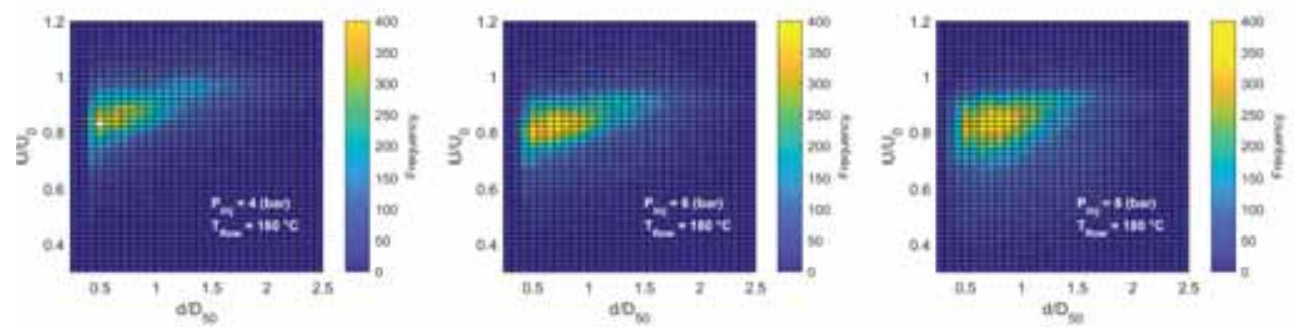

Figure 22: Average spray angle during the stable phase of the injection event.

The bottom part of Figure 22 shows three projections from the top view, which gives a good idea of the Diameter-Velocity trend. In general, from the three plots the majority of the droplets are smaller that the MMD and travel at a lower velocity than the theoretical $U_{o}$. From a practical point of view this could have some implications when the boundary conditions are imposed for CFD calculations.

This scattered distribution could be important when the evaporation rate wants to be determined because, as Birkhold suggested in [29], small droplets do not penetrate as much as bigger droplets and evaporate and decompose faster, resulting in a temperature drop and an increase of the concentration of water vapour and $\mathrm{NH}_{3}$ far from the nozzle where this phenomena occurs, affecting the de-NOx process in the catalytic converter.

The influence of the injection pressure over the number of droplets is clear, as this parameter increases the number of droplets also increases.

\section{Conclusions}

An experimental methodology to analyse the atomization of a UWS spray injected in similar engine exhaust conditions is presented. The experiments were carried out in a test rig capable of reaching high temperatures and gas mass flow. The optical accesses of the facility allowed the measurement of the microscopic properties of the spray using the DBI technique at high imaging speed. Three measuring windows were selected for the characterization: one very close to the 
nozzle exit, and the other two in the developed region of the spray (in the axis of the plume and in the periphery of the spray in the direction of the flow). From the images, the droplet diameter distribution and velocity under different conditions of injection pressure and gas temperature were determined. The velocity of the droplets was calculated using a droplet tracking algorithm. The interest in the technique is that the setup is relatively easy and that the velocity can be determined in two components at the same time.

The droplet diameter and velocity are affected by injection pressure. Differences were seen at the three positions of the spray. Near the nozzle exit, higher injection pressure produced more amount of droplets with smaller diameter. In regions further away from the injector, the influence of the pressure was less notorious. Also, at the developed zone of the spray the distribution of particle size showed a higher concentration of droplets with small diameter, evidencing that some atomization process or evaporation took place.

The droplet velocity distribution in the injector axis ( $\mathrm{Y}$ component) showed a wider range of velocity as the injection pressure rose. As the region of interest was set in the developed zone of the spray, the velocity distribution became similar in shape, but still with higher values for higher pressures as expected. The velocity distribution in the flow direction (X component) depended on injection pressure in the region near to the nozzle exit, with wider shape (negative and positive values) at high pressure that can be related to some degree of turbulence inside the nozzle, moving the flow in the radial component and corroborating the wider global spray angle behaviour.

The gas temperature has an effect on the velocity distribution in the developed spray zone. The increase of velocity at high flow temperature could be attributed to the change of properties in the gas mass flow, allowing the droplets to penetrate the chamber faster in both directions.

From a qualitative point of view, the raw images showed that in locations near the nozzle exit there were regions of liquid with non-spherical structures, like blobs or ligaments, that were still breaking up. On the other hand, in the frames registered in the developed zone of the spray most of the droplets were 
spherical, more uniform and smaller than in the first position. Future works will be done using this setup with the intention of exploring more positions and different injector parameters that could affect the behaviour of the spray characteristics.

\section{Acknowledgments}

The equipment used for the experiments was financially supported by IDIFEDER2018 from Generalitat Valenciana. The author A. Moreno thanks the Universitat Politècnica de València for his predoctoral contract (FPI-2018-S2-

13), which is included within the framework of Programa de Apoyo para la Investigación y Desarrollo (PAID).

\section{References}

[1] T. Johnson, A. Joshi, Review of Vehicle Engine Efficiency and Emissions, SAE Technical Paper Series 1 (2018) 1-23 (2018). doi:10.4271/ 2018-01-0329.

URL http://papers.sae.org/2017-01-0907/

[2] B. Degraeuwe, M. Weiss, Does the New European Driving Cycle (NEDC) really fail to capture the NOX emissions of diesel cars in Europe?, Environmental Pollution 222 (X) (2017) 234-241 (2017). doi:10.1016/j .envpol. 2016.12 .050 .

URL http://dx.doi.org/10.1016/j.envpol.2016.12.050

[3] L. Yang, V. Franco, P. Mock, R. Kolke, S. Zhang, Y. Wu, J. German, Experimental Assessment of NOx Emissions from 73 Euro 6 Diesel Passenger Cars, Environmental Science and Technology 49 (24) (2015) 14409-14415 (2015). doi:10.1021/acs.est.5b04242.

[4] G. Triantafyllopoulos, D. Katsaounis, D. Karamitros, L. Ntziachristos, Z. Samaras, Experimental assessment of the potential to decrease diesel 
NOxemissions beyond minimum requirements for Euro 6 Real Drive Emissions (RDE) compliance, Science of the Total Environment 618 (x) (2018) 1400-1407 (2018). doi:10.1016/j.scitotenv.2017.09.274.

URL https://doi.org/10.1016/j.scitotenv.2017.09.274

[5] G. Zheng, Development of Air-Assisted Urea Injection Systems for Medium Duty Trucks, SAE Technical Paper Series 1 (2017). doi:10.4271/ 2017-24-0112.

[6] M. Koebel, M. Elsener, M. Kleemann, Urea-SCR: a promising technique to reduce NOx emissions from automotive diesel engines, Catalysis Today 59 (3) (2000) 335-345 (2000). doi:10.1016/S0920-5861(00)00299-6.

URL http://linkinghub.elsevier.com/retrieve/pii/ S0920586100002996

[7] J. Oh, K. Lee, Spray characteristics of a urea solution injector and optimal mixer location to improve droplet uniformity and NOx conversion efficiency for selective catalytic reduction, Fuel 119 (2014) 90-97 (2014). doi:10. 1016/j.fuel.2013.11.032.

URL http://dx.doi.org/10.1016/j.fuel.2013.11.032

[8] A. Varna, A. C. Spiteri, Y. M. Wright, P. Dimopoulos Eggenschwiler, K. Boulouchos, Experimental and numerical assessment of impingement and mixing of urea-water sprays for nitric oxide reduction in diesel exhaust, Applied Energy 157 (2015) 824-837 (2015). doi:10.1016/j.apenergy . 2015.03 .015$.

URL http://dx.doi.org/10.1016/j.apenergy .2015.03.015

[9] L. Postrioti, N. van Vuuren, C. Ungaro, G. Brizi, G. Buitoni, AUS-32 Injector Spray Imaging on Hot Air Flow Bench, SAE Technical Paper Series 1 (2015). doi : 10.4271/2015-01-1031.

[10] N. van Vuuren, L. Postrioti, G. Brizi, C. Ungaro, G. Buitoni, Experimental Analysis of the Urea-Water Solution Temperature Effect on the Spray 
Characteristics in SCR Systems, SAE Technical Paper Series 1 (2015). doi:10.4271/2015-24-2500.

[11] M. Lecompte, S. Raux, A. Frobert, Experimental Characterization of SCR DeNOx-Systems: Visualization of Urea-Water-Solution and Exhaust Gas Mixture, SAE Technical Paper Series 1 (2014). doi:10.4271/ 2014-01-1524.

URL http://papers.sae.org/2014-01-1524/

[12] A. Spiteri, P. Dimopoulos Eggenschwiler, Experimental fluid dynamic investigation of urea-water sprays for diesel selective catalytic reductiondenox applications, Industrial and Engineering Chemistry Research 53 (8) (2014) 3047-3055 (2014). doi:10.1021/ie404037h.

[13] Y. Liao, R. Furrer, P. Dimopoulos Eggenschwiler, K. Boulouchos, Experimental investigation of the heat transfer characteristics of spray/wall interaction in diesel selective catalytic reduction systems, Fuel 190 (2017) 163-173 (2017). doi:10.1016/j.fuel.2016.11.035.

URL http://dx.doi.org/10.1016/j.fuel.2016.11.035

[14] L. Postrioti, G. Brizi, C. Ungaro, M. Mosser, F. Bianconi, A methodology to investigate the behaviour of urea-water sprays in high temperature air flow for SCR de-NOxapplications, Fuel 150 (x) (2015) 548-557 (2015). doi : $10.1016 / j$.fuel.2015.02.067.

URL http://dx.doi.org/10.1016/j.fuel.2015.02.067

[15] R. Payri, J. Gimeno, G. Bracho, A. Moreno, Spray characterization of the Urea-Water Solution ( UWS ) injected in a hot air stream analogous to SCR system operating conditions ., WCX SAE World Congress Experience (2019-01-0738) (2019) 1-9 (2019). doi:10.4271/2019-01-0738. Abstract.

[16] R. Payri, J. Gimeno, M. Bardi, A. H. Plazas, Study liquid length penetration results obtained with a direct acting piezo electric injector, Applied 
Energy 106 (JUNE) (2013) 152-162 (2013). doi:10.1016/j.apenergy . 2013.01 .027$.

URL http://dx.doi.org/10.1016/j.apenergy . 2013.01.027

[17] R. Payri, F. J. Salvador, J. Gimeno, L. D. Zapata, Diesel nozzle geometry influence on spray liquid-phase fuel penetration in evaporative conditions, Fuel 87 (7) (2008) 1165-1176 (2008). doi:10.1016/j.fuel.2007.05.058. URL http://www.sciencedirect.com/science/article/pii/ S0016236107003080

[18] R. Payri, J. P. Viera, V. Gopalakrishnan, P. G. Szymkowicz, The effect of nozzle geometry over the evaporative spray formation for three different fuels, Fuel 188 (2017) 645-660 (2017). doi:10.1016/j .fuel.2016.06.041. URL http://dx.doi.org/10.1016/j.fuel.2016.10.064

[19] R. Payri, F. J. Salvador, J. De la Morena, V. Pagano, Experimental investigation of the effect of orifices inclination angle in multihole diesel injector nozzles. Part 2 - Spray characteristics, Fuel 213 (2018) 215-221 (2018). doi:10.1016/j.fuel.2017.07.076.

[20] D. L. Siebers, Scaling Liquid-Phase Fuel Penetration in Diesel Sprays Based on Mixing-Limited Vaporization, SAE Technical Paper Series 1 (2010). doi: 10.4271/1999-01-0528.

URL http://subscriptions.sae.org/content/1999-01-0528/

[21] J. Manin, M. Bardi, L. M. Pickett, R. N. Dahms, J. C. Oefelein, Microscopic investigation of the atomization and mixing processes of diesel sprays injected into high pressure and temperature environments, Fuel 134 (2014) 531-543 (2014). doi:10.1016/j.fuel.2014.05.060.

URL http://dx.doi.org/10.1016/j.fuel.2014.05.060

[22] J. B. Blaisot, J. Yon, Droplet size and morphology characterization for dense sprays by image processing: Application to the Diesel spray, Experiments in Fluids 39 (6) (2005) 977-994 (2005). doi:10.1007/ 
s00348-005-0026-4.

URL http://link. springer.com/10.1007/s00348-005-0026-4http://

link. springer.com/article/10.1007/s00348-005-0026-4

[23] C. Tang, Z. Feng, C. Zhan, W. Ma, Z. Huang, Experimental study on the effect of injector nozzle $\mathrm{K}$ factor on the spray characteristics in a constant volume chamber: Near nozzle spray initiation, the macroscopic and the droplet statistics, Fuel 202 (2017) 583-594 (2017). doi:10.1016/j.fuel. 2017.04 .078$.

URL http://dx.doi.org/10.1016/j.fuel.2017.04.078

[24] Ł. J. Kapusta, A. Teodorczyk, Laser diagnostics for urea-water solution spray characterization, MATEC Web of Conferences 118 (00029) (2017) 00029 (2017). doi:10.1051/matecconf/201711800029.

URL https://ww. matec-conferences.org/articles/ matecconf/abs/2017/32/matecconf\{_\}icce2017\{_\}00029/

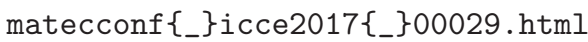

[25] L. J. Kapusta, LIF/Mie Droplet Sizing of Water Sprays from SCR System Injector using Structured Illumination, Proceedings of ILASS2017 - 28th European Conference on Liquid Atomization and Spray Systems (September) (2017) 580-587 (2017). doi:10.4995/ilass2017.2017.5031.

URL http://ocs.editorial.upv.es/index.php/ILASS/ILASS2017/ paper/view/5031

[26] Z. Zhao, G. Zheng, F. Wang, S. Zhang, J. Zhang, Development of Injector Closely-Coupled SCR System for Horizontal Inlet Configurations SCR System With Injector Closed-Coupled, SAE International (x) (2018). doi:10.4271/2014-01-2350. Copyright.

[27] J. Mutyal, S. Shrivastava, R. Faltsi, M. Braun, Development and Validation of a Simulation Model for Urea-Water-Solution Decomposition for Automotive SCR Systems, SAE Technical Paper Series 1 (2015-01-2795) (2015). doi:10.4271/2015-01-2795. 
[28] A. H. Lefebvre, V. G. McDonell, Atomization and Sprays., Vol. 45, CRC Press, 1990 (1990). doi:10.1016/0009-2509(90) 87140-N.

URL http://linkinghub.elsevier.com/retrieve/pii/ 000925099087140N

[29] F. Birkhold, U. Meingast, P. Wassermann, O. Deutschmann, Modeling and simulation of the injection of urea-water-solution for automotive SCR DeNOx-systems, Applied Catalysis B: Environmental 70 (1-4) (2007) 119127 (2007). doi:10.1016/j. apcatb.2005.12.035. 